\title{
Polymorphic microsatellite loci for the genetic analysis of Lycoris radiata (Amaryllidaceae) and cross-amplification in other congeneric species
}

\author{
S.Q. Xuan ${ }^{1}$, J.Y. Zheng ${ }^{1}$, H. Wang, ${ }^{1,2}$, P. Gao ${ }^{1}$, S.B. Zhou ${ }^{1,2}$, K. Liu ${ }^{1,2}$ \\ and G.-P. Zhu ${ }^{1,2}$ \\ ${ }^{1}$ Key Laboratory of Molecular Evolution and Biodiversity, \\ Institute of Molecular Biology and Biotechnology, \\ Anhui Normal University, Wuhu, P.R. China \\ ${ }^{2}$ Anhui Provincial Key Laboratory of the Conservation and Exploitation of \\ Biological Resources, Anhui Normal University, Wuhu, P.R. China \\ Corresponding author: G.-P. Zhu \\ E-mail: gpz1996@yahoo.com
}

Genet. Mol. Res. 10 (4): 3141-3145 (2011)

Received January 10, 2011

Accepted May 16, 2011

Published December 19, 2011

DOI http://dx.doi.org/10.4238/2011.December.19.2

\begin{abstract}
Lycoris radiata is a perennial herb that has been used in traditional Chinese medicine for a long time and has two main medicinal components in its bulb, lycorine and galanthamine. However, the original microsatellite loci have not been developed for any species of Lycoris. Total genomic DNA was extracted from fresh bulbs using a modified CTAB protocol. We isolated 10 microsatellite loci from 21 L. radiata individuals of a natural population from Yellow Mountain in Anhui Province, China. The number of alleles ranged from two to nine. The observed and expected heterozygosities ranged from 0.238 to 0.952 and from 0.455 to 0.784 , respectively. One locus significantly deviated from Hardy-Weinberg equilibrium and no significant linkage disequilibrium was found between pairs of loci. Cross-species amplification of these microsatellite loci was characterized in additional five species (L. sprengeri, L. anhuiensis, L. albiflora, L. longituba, and
\end{abstract}


L. chinensis) of Lycoris. The results suggest that these microsatellite markers would contribute to the population genetic studies of $L$. radiata and other related species.

Key words: Lycoris radiata; Microsatellite; Molecular marker; Cross-amplification

\section{INTRODUCTION}

Lycoris radiata is a perennial herb grown from small bulbs. The plant prefers shady and moist areas and is mainly distributed in the middle and lower reaches of the Yangtze River in China and other countries in Southeast Asia (Ji and Meerow, 2000). Their bulbs have been used in traditional Chinese medicine for a long time. There are two main medicinal components in the bulbs, lycorine and galanthamine. Galanthamine has been widely used in medicine as a strong reversible inhibitor of cholinesterase to increase acetylcholine sensitivity (Novikova1 and Tulaganov, 2002). It has also been used in the treatment of glaucoma (Harvey, 1995) and Alzheimer's disease (Harvey, 1995; Bores et al., 1996). Furthermore, L. radiata is of great interest to horticulturists due to its scarlet flowers in autumn and green leaves all winter long. The morphology of $L$. radiata has been extensively studied, including pollen (Zhou et al., 2005) and leaf morphology (Zhou et al., 2007a) and karyotype analysis (Zhou et al., 2007b). However, studies on molecular phylogeny and population genetics are very scarce. Microsatellites are widely distributed across genomes and inherit in a codominant Mendelian manner and display high levels of polymorphism (Li et al., 2002; Menezes et al., 2009). They have been developed into one of the most popular genetic markers used in parentage, genomic mapping, evolutionary population genetics, conservation biology, and other studies (Rao et al., 2000; Ellegren, 2004; Jarvis et al., 2008; Peng et al., 2009). However, the original microsatellite loci have not been developed for any species of Lycoris. In this study, 10 polymorphic microsatellite DNA markers were developed from L. radiata using a modified biotin-capture method (Bloor et al., 2001).

\section{MATERIAL AND METHODS}

Total genomic DNA was extracted from fresh bulbs using a modified cetyltrimethyl ammonium bromide (CTAB) protocol (Doyle and Doyle, 1987; Varma et al., 2007). The enriched partial genomic library for the repeat motif $(\mathrm{CT})_{15}$ was constructed using the individual DNA and the microsatellite-enriched DNA fragments were captured by a modified biotin-capture method (Bloor et al., 2001). Briefly, genomic DNA was digested with Sau3AI (TaKaRa). DNA fragments between 300 and $900 \mathrm{bp}$ were isolated on $1.2 \%$ agarose gel and ligated to the Sau3AI adaptors oligoA (5'-GGCCAGAGACCCCAAGCTTCG-3') and oligoB (5'PO4GATCCGAAGCTTGGGGTCTCTGGCC-3') (Bloor et al., 2001). Then, DNA fragments were amplified by polymerase chain reaction (PCR) using oligoA primers. The genomic DNA fragments containing simple-sequence repeats (SSR) were hybridized to the single-stranded 3'-biotinylated $(\mathrm{CT})_{15}$ oligonucleotide probes and captured by streptavidin-coated beads (Promega). Captured fragments were ligated to pMD18-T vector (TaKaRa) and transformed into Escherichia coli DH5 $\alpha$ competent cells according to the standard protocol. PCRs using oligoA 
and oligonucleotides $(\mathrm{CT})_{15}$ as the primers were employed to identify insert-positive clones. The clones that yielded two or more bands contained microsatellite fractions, as shown in Figure 1. Sixty-six positive clones were screened and sequenced using the ABI PRISM 3730 automated DNA sequencer. Forty-five clones were successfully sequenced and 40 sequences contained repeat motifs. Thirty-three pairs of primers were designed using the PRIMER PREMIER 5.0 software (http://www.premierbiosoft.com/) and synthesized.

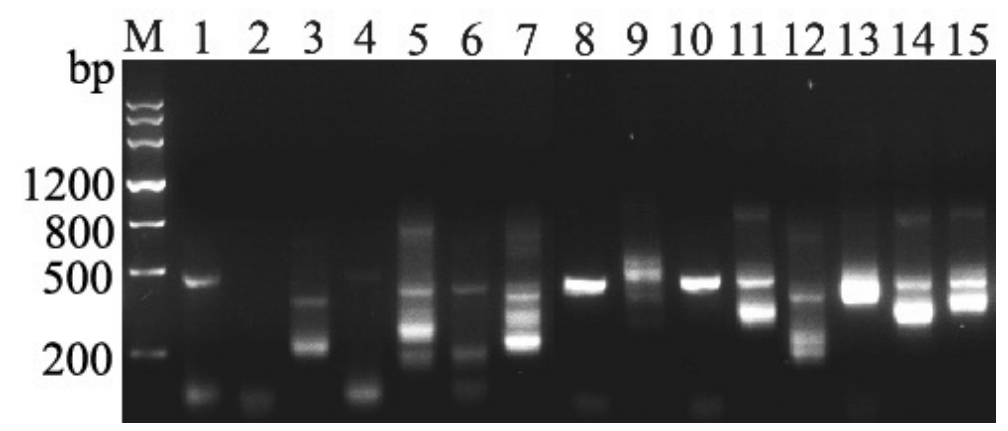

Figure 1. Agarose gel showing the representative identification of captured fragment insert-positive clones. Lane $M=$ molecular marker; lanes 1-15 = PCRs to identify insert-positive clones using oligoA and oligonucleotides $(\mathrm{CT})_{15}$ as the primers.

Polymorphism at each locus was determined using 21 individuals from a natural population from Yellow Mountain (Mt. Huangshan) in Anhui Province. PCR amplifications (15 $\mu \mathrm{L})$ contained 6.25 $\mu \mathrm{L} \mathrm{GoTaq}{ }^{\circledR}$ Green Master Mix (Promega, China), 0.5-1.0 $\mu$ mol of each primer and 10-20 ng DNA, and were performed in an iCycler thermocycler (Bio-Rad). The cycling parameters were 4 min at $94^{\circ} \mathrm{C}$ followed by 35 cycles of $45 \mathrm{~s}$ at $94^{\circ} \mathrm{C}, 35 \mathrm{~s}$ at the optimized annealing temperature (Table 1) and $30 \mathrm{~s}$ at $72^{\circ} \mathrm{C}$. The final extension was $8 \mathrm{~min}$ at $72^{\circ} \mathrm{C}$. The PCR products were separated on $8 \%$ denaturing polyacrylamide gels (acrylamide:bisacrylamide, 19:1) using a LI-COR 4200 automated DNA sequencer and analyzed using the LI-COR SAGA ${ }^{\mathrm{GT}}$ software. GENEPOP version 4.0 (Raymond and Rousset, 1995) was used to calculate the number of alleles $\left(N_{\mathrm{A}}\right)$, observed $\left(H_{\mathrm{O}}\right)$ and expected $\left(H_{\mathrm{E}}\right)$ heterozygosities, Hardy-Weinberg equilibrium expectation (HWE), and linkage disequilibrium. All results for multiple tests were corrected using Bonferroni's correction (Rice, 1989).

\section{RESULTS AND DISCUSSION}

Ten polymorphic microsatellite loci from the microsatellite-enriched genomic library were newly developed across $21 \mathrm{~L}$. radiata individuals. Details are summarized in Table 1. The 10 sequences containing microsatellite loci were deposited in GenBank (HQ697319HQ697328), and no similarity was found between the 10 microsatellites and the sequences published in GenBank. The $N_{\mathrm{A}}$ per locus ranged from 2 to 9 . The $H_{\mathrm{O}}$ and $H_{\mathrm{E}}$ ranged from 0.238 to 0.952 and from 0.455 to 0.784 , respectively. The remaining 23 loci were monomorphic and failed to amplify. Nine loci conformed to HWE and one locus (Lyra-7) significantly deviated from HWE expectations in the sampled population after Bonferroni's correction (adjusted $\mathrm{P}$ value $=0.0044$ ) . Lyra-7 deviated from HWE, which could be due to the presence of null alleles 
that was confirmed by the analyses using the MICRO-CHECKER software (Van Oosterhout et al., 2004) (Bonferroni's correction). None of the loci showed significant linkage disequilibrium.

\begin{tabular}{|c|c|c|c|c|c|c|c|c|}
\hline Locus & Repeat motif & Primer sequence (5'-3') & $\mathrm{Ta}\left({ }^{\circ} \mathrm{C}\right)$ & $\begin{array}{l}\text { Allele } \\
\text { size (bp) }\end{array}$ & $N_{\mathrm{A}}$ & $H_{\mathrm{O}}$ & $H_{\mathrm{E}}$ & $\begin{array}{c}\text { GenBank } \\
\text { accession No. }\end{array}$ \\
\hline Lyra-1 & $(\mathrm{CT})_{16}$ & $\begin{array}{l}\text { F: TCTGTTCACCTTTACCCTCTC } \\
\text { R: CAGCCTCAACTCCAATCTCG }\end{array}$ & 57 & $131-197$ & 6 & 0.524 & 0.657 & HQ697319 \\
\hline Lyra-2 & $(\mathrm{TC})_{35}$ & $\begin{array}{l}\text { F: CCATCGCCGCTACTATCAC } \\
\text { R: AAAGGAGAAGAGGGTATCAAC }\end{array}$ & 56 & $180-232$ & 9 & 0.762 & 0.784 & HQ697320 \\
\hline Lyra-3 & $(\mathrm{CT})_{24}$ & $\begin{array}{l}\text { F: CCAATGTTCACTACCACCCC } \\
\text { R: GAAGGTTTTGGTTTCAGGAT }\end{array}$ & 53 & $200-300$ & 4 & 0.571 & 0.672 & HQ697321 \\
\hline Lyra-4 & $(\mathrm{TC})_{31}$ & $\begin{array}{l}\text { F: CCTTGCTCACGACTCCTTTA } \\
\text { R: CCAATGCTGTTGCCACCTTC }\end{array}$ & 60 & $306-350$ & 5 & 0.905 & 0.740 & HQ697322 \\
\hline Lyra-5 & $(\mathrm{TC})_{12} \mathrm{C}(\mathrm{CT})_{7}$ & $\begin{array}{l}\text { F: CCTTCTTTGGCTACTCACAT } \\
\text { R: CAGTCAGTCCATCCTCTTGC }\end{array}$ & 59 & $265-297$ & 4 & 0.952 & 0.700 & HQ697323 \\
\hline Lyra-6 & $(\mathrm{TC})_{19}$ & $\begin{array}{l}\text { F: CATCCCCTCCCCGAACTAT } \\
\text { R: GCTTCTCACCGCCGCTAAT }\end{array}$ & 59 & $288-316$ & 2 & 0.286 & 0.455 & HQ697324 \\
\hline Lyra-7* & $(\mathrm{AG})_{19}$ & $\begin{array}{l}\text { F: GGGTGATGAAATGAACTG } \\
\text { R: ACTCCTATTGCCACCCTC }\end{array}$ & 53 & $224-262$ & 3 & 0.238 & 0.528 & HQ697325 \\
\hline Lyra-8 & $(\mathrm{AG})_{7} \mathrm{~N}(\mathrm{GA})_{19}$ & $\begin{array}{l}\text { F: CAGTCGCTAAACTAAGCCCTAT } \\
\text { R: CCCACAACTTGCCTTCCTCT }\end{array}$ & 59 & $225-287$ & 6 & 0.619 & 0.740 & HQ697326 \\
\hline Lyra-9 & $(\mathrm{GA})_{24}$ & $\begin{array}{l}\text { F: AACTCCAACCACCCTTTA } \\
\text { R: ACTTGCCTTCCTCTTTCT }\end{array}$ & 54 & $257-297$ & 5 & 0.524 & 0.698 & HQ697327 \\
\hline Lyra-10 & $(\mathrm{CT})_{22}$ & $\begin{array}{l}\text { F: TCGCTCAACTTACCTCTA } \\
\text { R: TGATTCCTCCATGCTTCT }\end{array}$ & 51 & $215-251$ & 3 & 0.524 & 0.463 & HQ697328 \\
\hline
\end{tabular}

Ta = optimized annealing temperature; $N_{\mathrm{A}}=$ number of alleles; $H_{\mathrm{O}}=$ observed heterozygosity; $H_{\mathrm{E}}=$ expected heterozygosity. *Indicates significant deviation from HWE after Bonferroni's correction $(\mathrm{P}<0.05)$.

Cross-species amplification of 10 microsatellite markers was carried out in five congeneric species: L. sprengeri, L. anhuiensis, L. albiflora, L. longituba, and L. chinensis. The same PCR conditions were used as described above except that the annealing temperature was re-optimized at each locus. Five individuals from each species were screened at 10 loci. Results are summarized in Table 2. Two loci (Lyra-5 and Lyra-6) were amplified successfully in all species, two loci (Lyra-1 and Lyra-2) were amplified in four species except $L$. sprengeri, and nine loci (except Lyra-10) were amplified in L. albiflora. These results suggest that the identified microsatellite markers will be useful in genetic studies of $L$. radiata and other species of Lycoris.

\begin{tabular}{|c|c|c|c|c|c|}
\hline Locus & L. sprengeri & L. anhuiensis & L. albiflora & L. longituba & L. chinensis \\
\hline Lyra-1 & - & $167-195$ & $153-207$ & $153-207$ & $147-200$ \\
\hline Lyra-2 & - & 200 & $168-200$ & $156-192$ & $152-192$ \\
\hline Lyra-3 & - & - & $216-262$ & 331 & - \\
\hline Lyra-4 & - & - & 285 & - & - \\
\hline Lyra-5 & 287 & $258-300$ & $225-287$ & $215-287$ & $240-300$ \\
\hline Lyra-6 & 315 & $320-350$ & $315-345$ & 348 & 348 \\
\hline Lyra-7 & - & - & $350-300$ & - & - \\
\hline Lyra-8 & 225 & - & 225 & - & - \\
\hline Lyra-9 & - & - & 262 & - & - \\
\hline Lyra-10 & 225 & 225 & - & - & 235 \\
\hline
\end{tabular}

Minus sign denotes no visible PCR product. 


\section{ACKNOWLEDGMENTS}

Research supported by the National Natural Science Foundation of China ( $\# 30870062$ and \#31040003), the Scientific Research Foundation for the Returned Overseas Chinese Scholars from State Education Ministry, the Key Laboratory of Biotic Environment and Ecological Safety in Anhui Province, and the Program for Innovative Research Team in Anhui Normal University.

\section{REFERENCES}

Bloor PA, Barker FS, Watts PC and Noyes HA (2001). Microsatellite Libraries by Enrichment. Available at [http://www. genomics.liv.ac.uk/animal/MICROSAT.PDF]. Accessed September 22, 2010.

Bores GM, Huger FP, Petko W, Mutlib AE, et al. (1996). Pharmacological evaluation of novel Alzheimer's disease therapeutics: acetylcholinesterase inhibitors related to galanthamine. J. Pharmacol. Exp. Ther. 277: 728-738.

Doyle JJ and Doyle JL (1987). A rapid DNA isolation procedure for small quantities of fresh leaf tissue. Phytochem Bull. 19: 11-15.

Ellegren H (2004). Microsatellites: simple sequences with complex evolution. Nat. Rev. Genet. 5: 435-445.

Harvey AL (1995). The pharmacology of galanthamine and its analogues. Pharmacol. Ther. 68: 113-128.

Jarvis DE, Kopp OR, Jellen EN, Mallory MA, et al. (2008). Simple sequence repeat marker development and genetic mapping in quinoa (Chenopodium quinoa Willd.). J. Genet. 87: 39-51.

Ji ZH and Meerow AW (2000). Amaryllidaceae. In: Flora of China, 24. Science Press, Beijing, and Missouri Botanical Garden Press, St. Louis.

Li YC, Korol AB, Fahima T, Beiles A, et al. (2002). Microsatellites: genomic distribution, putative functions and mutational mechanisms: a review. Mol. Ecol. 11: 2453-2465.

Menezes IC, Cidade FW, Souza AP and Sampaio IC (2009). Isolation and characterization of microsatellite loci in the black pepper, Piper nigrum L. (piperaceae). Conservat. Genet. Resour. 1: 209-212.

Novikova IY and Tulaganov AA (2002). Physicochemical methods for the analysis of galanthamine (review). Pharmaceut. Chem. J. 36: 623-627.

Peng YQ, Shao JW, Wu HL, Zhang XP, et al. (2009). Isolation and characterization of fifteen polymorphic microsatellite loci from Primula merrilliana (Primulaceae), an endemic from China. Conserv. Genet. 10: 1441-1443.

Raymond M and Rousset F (1995). GENEPOP (version 1.2): Population genetics software for exact tests and ecumenicism. J. Hered. 86: 248-249.

Rice WE (1989). Analyzing tables of statistical tests. Evolution 43: 223-225.

Roa AC, Chavarriaga-Aguirre P, Duque MC, Maya MM, et al. (2000). Cross-species amplification of cassava (Manihot esculenta) (Euphorbiaceae) microsatellites: allelic polymorphism and degree of relationship. Am. J. Bot. 87: 1647-1655.

Van Oosterhout C, Hutchinson WF, Wills DPM and Shipley P (2004). MICRO-CHECKER: software for identifying and correcting genotyping errors in microsatellite data. Mol. Ecol. Notes 4: 535-538.

Varma A, Padh H and Shrivastava N (2007). Plant genomic DNA isolation: an art or a science. Biotechnol. J. 2: 386-392.

Zhou SB, Yu B, Luo Q, Qin W, et al. (2005). Pollen morphology of Lycoris Herb. and its taxonomic significance. Acta Hortic. Sin. 32: 914-917.

Zhou SB, Luo Q, Li JH and Wang Y (2007a). Comparative anatomy of leaves in 12 species of Lycoris (Amaryllidaceae). Acta Bot. Yunnanica 28: 473-480.

Zhou SB, Yu B-Q, Luo Q, Hu J-R, et al. (2007b). Karyotypes of six populations of Lycoris radiata and discovery of the tetraploid. Acta Phytotaxon. Sin. 45: 513-522. 